\title{
Review of concepts in therapeutic decision-making in HER2-negative luminal metastatic breast cancer
}

\author{
I. Alvarez-Lopez ${ }^{1,2}$ (1) S. Bezares ${ }^{2}$ - E. Dalmau Portulas ${ }^{2,3} \cdot$ E. García-Martínez ${ }^{2,4} \cdot$ J. Á. García-Sáenz ${ }^{2,5,6} \cdot$ M. Gil-Gil $^{2,7}$. \\ E. Martínez de Dueñas ${ }^{2,8} \cdot$ N. Ribelles ${ }^{2,9,10} \cdot$ A. Santaballa Bertrán ${ }^{2,11}$
}

Received: 30 October 2019 / Accepted: 8 December 2019 / Published online: 12 February 2020

(c) The Author(s) 2020

\begin{abstract}
Purpose Hormone receptor (HR)-positive, Human epidermal growth factor receptor 2 (HER2)-negative metastatic breast cancer (MBC) requires a therapeutic approach that takes into account multiple factors, with treatment being based on antiestrogen hormone therapy (HT). As consensus documents are valuable tools that assist in the decision-making process for establishing clinical strategies and optimize the delivery of health services, this consensus document has been created with the aim of developing recommendations on cretiera for hormone sensitivity and resistance in HER2-negative luminal MBC and facilitating clinical decision-making.

Methods This consensus document was generated using a modification of the RAND/UCLA methodology, which included the definition of the project and identification of issues of interest, a non-exhaustive systematic review of the literature, an analysis and synthesis of the scientific evidence, preparation of recommendations, and external evaluation with a panel of 64 medical oncologists specializing in breast cancer.

Results A Spanish panel of experts reached consensus on 32 of the 32 recommendations/conclusions presented in the first round and were accepted with an approval rate of $100 \%$ about definition of metastatic disease not susceptible to local curative treatment, definition of hormone sensitivity and hormone resistance in metastatic luminal disease and therapeutic decision-making.

Conclusion We have developed a consensus document with recommendations on the treatment of patients with HER2negative luminal MBC that will help to improve therapeutic benefits.
\end{abstract}

Keywords Consensus · Metastatic breast cancer $\cdot$ Luminal $\cdot$ Hormonal therapy $\cdot$ Hormonal receptor $\cdot$ Hormonal resistance

I. Alvarez-Lopez

isabelmanuela.alvarezlopez@ osakidetza.eus

1 Hospital Universitario Donostia-BioDonostia, Begiristain Doktorea Pasealekua, 109, 20014 Donostia, Gipuzkoa, Spain

2 Grupo GEICAM de Investigación en Cáncer de Mama/GEICAM Spanish Breast Cancer Group, San Sebastián de los Reyes, Madrid, Spain

3 Parc Taulí, Hospital Universitari, Sabadell, Barcelona, Spain

4 Hospital General Universitario Morales Meseguer, Murcia, Spain

5 Hospital Clínico San Carlos, Madrid, Spain
6 Centro de Investigación Biomédica en Red de Oncología, CIBERONC-ISCIII, Madrid, Spain

7 ICO Bellvitge, Hospitalet del Llobregat, Barcelona, Spain

8 Consorcio Hospitalario Provincial de Castellón, Castellón de la Plana, Spain

9 Unidad de Gestión Clínica Intercentros de Oncología Medica, Hospitales Universitarios Regional y Virgen de la Victoria de Málaga, 29010 Málaga, Spain

10 Instituto de Investigación Biomédica de Málaga (IBIMA)-CIMES-UMA, 29010 Málaga, Spain

11 Hospital Universitario y Politécnico La Fe, Valencia, Spain 


\section{Introduction}

Breast cancer accounts for $30 \%$ of all cancers of the female gender, and is the most common malignancy in women and the main cause of cancer death. In Spain, the age-adjusted annual incidence is 125.8 cases $/ 100,000$ inhabitants and the mortality rate is 22.7 cases $/ 100,000$ inhabitants [1]; 32,825 new cases were diagnosed in 2018 [2, 3].

Between 5 and $6 \%$ of breast cancer patients have metastatic disease at the time of diagnosis, and approximately $30 \%$ of patients diagnosed in the early stages will experience a relapse with the appearance of distant metastases [4]. Most patients diagnosed with MBC are postmenopausal women between 50 and 79 years of age (64-79\%) [4]. Overall survival (OS) varies according to each biological subtype, and in the HR-positive, HER2-negative subgroup, median OS is 42 months. At present, $\mathrm{MBC}$ is still incurable and the main treatment goal is to improve OS and quality of life [5].

Treatment response in MBC depends mainly on the biological subtype. In the HR-positive, HER2-negative subtype, several factors play a significant role, including status at diagnosis ("de novo" or relapse after treatment of local disease), previous treatment for local disease, time to relapse, response to previous treatments for disseminated disease, time to next progression, progression-free survival (PFS), and hormone sensitivity criteria in patients with tumors that express hormone receptors. The first-line treatment recommended for patients with HR-positive, HER2-negative MBC is HT combined with cyclin-dependent kinase 4/6 (CDK4/6) inhibitors. The best HT option is determined by different factors, such as menopausal status, previous HT, and comorbidities. Clinical benefit from HT predicts patient survival and the possible benefit of subsequent HT [6]. It is estimated that approximately one-third of HR-positive patients present primary resistance to HT, the vast majority of whom develop secondary resistance. However, these same patients may respond to other types of HT. Therefore, the second-, third-, and fourth-line HT is administered sequentially, as resistance develops and the disease progresses $[6,7]$. Despite the fact that new parameters defining hormone sensitivity have been described [7], hormone sensitivity and resistance criteria based on clinical criteria and agreed by expert consensus have now been adopted, even in the absence of definitive biological data other than the expression or non-expression of HR-positive, HER2-negative receptors [8]. A full definition of these criteria would help optimize health-care processes and improve decision-making in the future.

Consensus documents are valuable tools that assist in the decision-making process for establishing clinical strategies and optimize the delivery of health services [9]. The preparation of this consensus document has been supported by the GEICAM Breast Cancer Research Group with the aim of developing recommendations on criteria for hormone sensitivity and resistance in HER2-negative luminal MBC and facilitating clinical decision-making.

\section{Materials and methods}

This consensus document was generated using a modification of the RAND/UCLA methodology [10]. The project phases were as follows. (1) Definition of the project and identification of issues of interest: objectives, methodology, and clinical questions to be answered in the consensus document were established. In addition, the working group was formed by a coordinator and a consensus group composed of seven oncologists, all experts in breast cancer who constituted the GEICAM working group on luminal disease between 2015 and 2018. (2) Non-exhaustive systematic review of the literature: we carried out a review of the scientific evidence from studies published between January 2000 and April 2016, in the following databases: PubMed, Guía Salud, Cochrane, Trip database, and Uptodate. The clinical questions were reformulated into questions using the PICO format (population/patients, intervention, comparators, outcomes) [11]. This search was complemented with a manual search of references by the consensus group aimed at completing the evidence with articles that could be helpful for answering the questions raised. (3) Analysis and synthesis of the scientific evidence: the members of the consensus group were responsible for systematically reviewing the available scientific evidence. After a critical reading of the full text of the selected studies, they prepared a summary using a standardized format, including tables and text to describe the methodology, the results, and the quality of each study. The reasons for exclusion of articles not included in the selection were listed. Scientific evidence and classification of the recommendations were evaluated according to the Oxford Center for Evidence-Based Medicine (CEBM) system [12]. (4) Preparation of recommendations: the consensus group drew up answers to the clinical questions from the scientific evidence and expert clinical judgment. All responses included the appropriate reasoning and proposed conclusion(s) and recommendation(s). (5) External evaluation: the recommendations/conclusions drawn up by the consensus group underwent a process of external validation using a two-round Delphi technique, with a panel of 64 medical oncologists specializing in breast cancer representing the validation group. In each round, the members of the validation group expressed their degree of agreement or disagreement with the recommendations/conclusions using an online questionnaire with a Likert scale of $1-4$ ( $1=$ strongly disagree; $4=$ strongly agree $)$. The recommendations with a level of agreement $\geq 80 \%$ [sum of scores of 3 (agree) and 4 (strongly agree)] were accepted. In total, 
all 32 of the 32 recommendations/conclusions presented in the first round were accepted (approval rate of 100\%).

\section{Results}

\section{Definition of metastatic disease or locoregional recurrence not susceptible to local curative treatment}

The luminal subtype is characterized by overexpression of estrogen receptors (ER) and/or progesterone receptors (PR). HR status is determined using immunohistochemical techniques on tumor biopsies. The tumor is considered HR positive if HR expression is detected in at least $1 \%$ of the nuclei of the invasive tumor cells. Staining in $\geq 10 \%$ of the nuclei indicates unambiguous positivity for the indication of HT; if staining is observed in 1-10\% of the nuclei, the pros and cons of HT must be weighed up. Tumors without ER expression but with positive PR expression should be considered RH-positive tumors that may benefit from HT $[13,14]$.

\section{Is it necessary to determine the intrinsic luminal subtype using gene expression platforms for therapeutic decision-making in luminal MBC?}

The clinical heterogeneity of breast cancer patients with positive HR is caused by the different gene expression profiles that define luminal subtypes A and B [15]. With regard to the classification of the tumor using gene platforms, such as PAM50, several studies have been performed to validate the results obtained with several variables of clinical interest. These studies have shown that it is possible to identify all intrinsic genomic subtypes in patients with HR-positive,
HER2-negative tumors [16, 17]. This genomic information should have greater prognostic value than conventional clinical and pathological data $[17,18]$, and genomic profiles are more effective than immunohistochemical techniques for identifying patients with luminal MBC that will respond to HT [PFS in patients with luminal subtype: 11.0-16.9 months; PFS in patients with non-luminal subtype: 4.1-4.7 months] [17]. The latest recommendations of the American Society of Clinical Oncology (ASCO) on HT in luminal MBC specify that intrinsic genomic subtypes have been associated with prognosis, but their usefulness for selecting the most effective treatment has not yet been demonstrated. Thus, the determination of intrinsic subtypes using genomic profiles is considered experimental and should be reserved for the selection of patients in the clinical trial setting [19].

\section{Can luminal $A$ and $B$ MBC subtypes be differentiated using immunohistochemical techniques?}

With the aim of associating genomic data with clinical and pathological characteristics, several studies have been conducted to establish differences in the receptor expression and proliferative status of tumors among the different luminal genomic subtypes using immunohistochemical techniques [20, 21]. Ki-67 was the marker selected to determine proliferation, defining positivity at a cutoff point of $14-20 \%$ $[20,22,23]$. The luminal subtype A would be defined by an expression below this cutoff point. PR levels have also been proposed as markers that might help discriminate between the two subtypes, with a cutoff point set at $20 \%$. Thus, tumors with more than $20 \%$ of PR-positive cells would be considered luminal A. Published evidence indicates that tumors with immunohistochemical luminal subtype

Table 1 Definitions of menopause from clinical practice guidelines

\begin{tabular}{ll}
\hline NCCN [100] & Prior bilateral oophorectomy \\
& $\geq 60$ years \\
& $<60$ years, and amenorrhea $\geq 12$ months in the absence of chemotherapy, tamoxifen, toremifene, \\
& or \\
& Ovarian suppression, and levels of FSH and estradiol within postmenopausal ranges \\
& In case of treatment with tamoxifen or toremifene and age $<60$ years, FSH and estradiol plasma \\
& levels must be within postmenopausal ranges ${ }^{\mathrm{a}}$ \\
& Lack of menstruation in the past 12 months in the absence of chemotherapy \\
& Oophorectomy, or \\
& Ovarian suppression with LHRH agonists \\
ASCO [19] & $>45$ years with no menstruation in the last 12 months and not taking hormonal contraception, or \\
& $>45$ years with hysterectomy and menopausal symptoms ${ }^{\mathrm{b}}$ \\
&
\end{tabular}

ASCO American Society of Clinical Oncology, FSH follicle-stimulating hormone, LHRH luteinizing hormone-releasing hormone, NCCN National Comprehensive Cancer Network, NICE National Institute for Health and Care Excellence

${ }^{a}$ A postmenopausal status cannot be assigned to women who are receiving LHRH antagonists

${ }^{\mathrm{b}}$ Only FSH levels will be analyzed to diagnose menopause when patients are between 40 and 45 years of age and present menopausal symptoms, including changes in menstrual cycle or age $<40$ years, suspicion of menopause, not receiving treatment with combination hormonal contraception (estrogen and progestin) or high doses of progestin 
A treated with HT may have a better response rate (RR), PFS, and overall survival (OS) post-relapse [16, 24-26] and appear to be less sensitive to treatment with chemotherapy [27] than luminal subtype B tumors.

\section{What are the criteria for defining menopause?}

It is essential that criteria for determining menopause are defined in patients with luminal breast cancer because, bearing in mind the mechanism of action of aromatase inhibitors (AIs), only patients that meet strict post-menopausal criteria will be candidates to receive these agents, in both early and metastatic disease [28]. The problem lies in the fact that the definition of menopause varies among the different clinical trials and research groups [29]. Menopause is a steep and permanent drop in ovarian estrogen synthesis, although this definition is not supported by any fixed criteria, particularly with regard to age or months of amenorrhea [30]. Several definitions of menopause are listed in Table 1.

\section{Should metastatic disease be biopsied at the time of its appearance and should the result guide the therapeutic decision?}

Traditionally, the levels of various biological markers in the primary tumor have guided systemic treatment in metastatic disease, but sometimes markers in metastatic disease can differ with respect to the primary tumor findings. A lesion suspected of being metastatic breast cancer might be benign or it might be a second malignant tumor, thus altering prognosis and treatment. Various prospective studies show that in $4-10 \%$ of cases, lesions suspected of being metastatic correspond in reality to healthy tissue, benign lesions, or a second malignant tumor, underlining the importance of biopsy for confirming the existence of breast cancer metastasis, particularly at the time of initial relapse. An analysis of the ConvertHER study using PAM50 confirmed changes in the molecular subtype between the primary tumor and the metastasis [31, 32]. A meta-analysis [33] of data from individual patients from two of these studies (DESTINY and BRITS) showed rates of conversion between the primary tumor and the metastasis of $6 \%, 13 \%$, and $31 \%$ for HER2, ER, and PR, respectively. The treatment plan was

Table 2 Recommendations and conclusions on the definition of metastatic or recurrent locoregional luminal disease not susceptible to curative local treatment

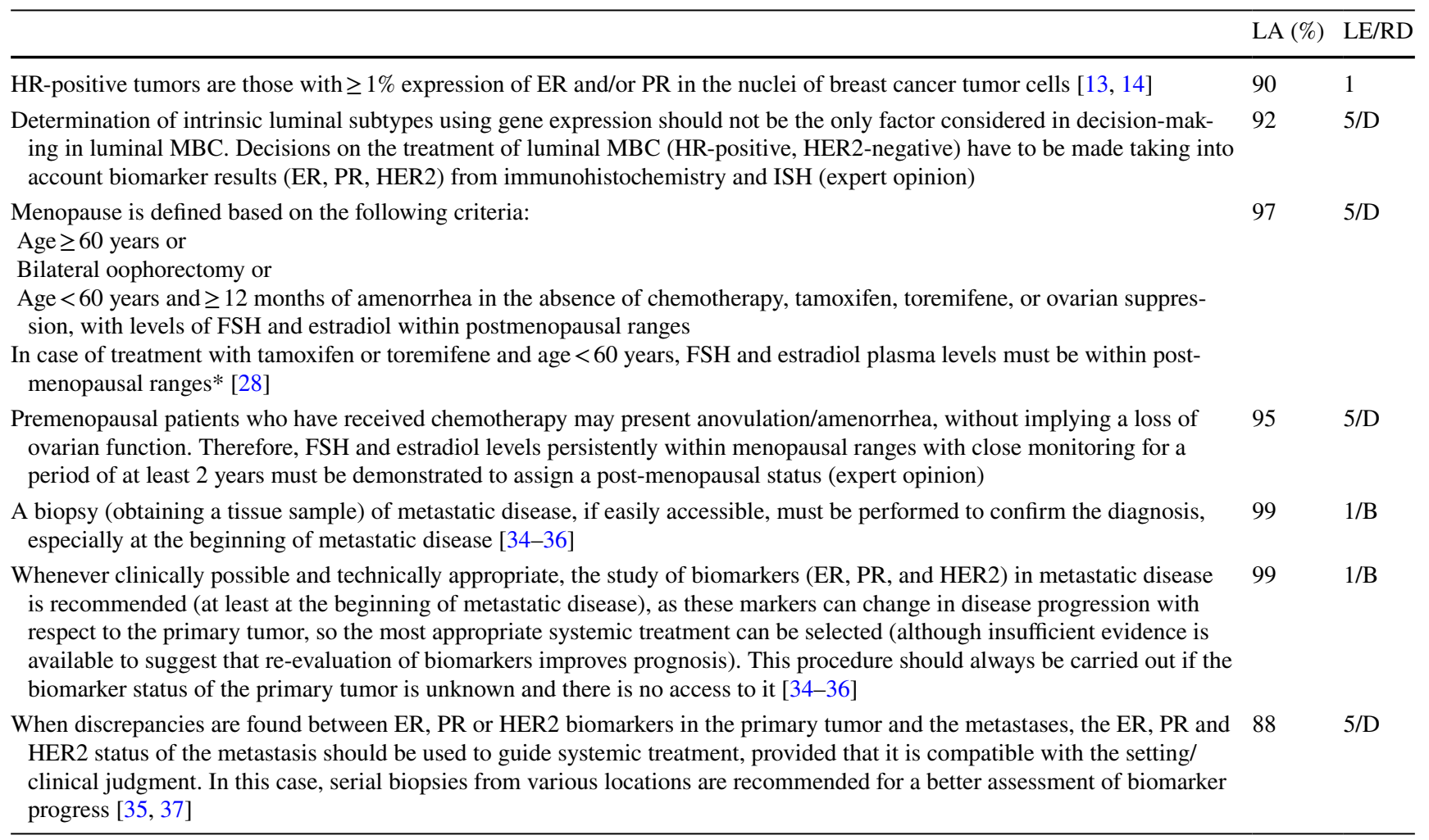

$E R$ estrogen receptor, $E S R 1$ estrogen receptor 1, HER2 human epidermal growth factor receptor 2, $H R$ hormone receptor, $L A$ level of agreement, $L E$ level of evidence, $M B C$ metastatic breast cancer, $N S A I$ non-steroidal aromatase inhibitors, $P R$ progesterone receptor, $R D$ recommendation degree according to Oxford 
modified in $8-14 \%$ of cases after biopsy. These results are similar to those obtained in the previous study. Most clinical guidelines recommend a biopsy of metastatic lesions (one or more) at the time of presentation of metastatic disease, to confirm the nature of the metastases and to re-evaluate HR and HER2 status [19, 34-36]. Caution should be exercised with the results obtained from tissue biopsies in which technical difficulties are a likelihood, such as bone biopsy $[8,19,34]$.

Table 2 shows the recommendations and conclusions of the expert group with regard to this topic.

\section{Definition of hormone sensitivity and hormone resistance in metastatic luminal disease}

\section{What variables can be used to set the definition of hormone sensitivity and hormone resistance in luminal MBC?}

It is of the utmost importance that variables determining hormone resistance are identified, both for making decisions in clinical practice and for interpreting clinical trials $[8,19$, 37-39]. In this setting, changes in HR expression in metastatic cells must be evaluated, although there is no evidence that these changes are predictive of response to any type of therapy [8, 19, 37, 40, 41]. Changes in HER2 expression in metastasis with respect to the primary tumor must also be taken into account. Several randomized clinical trials have demonstrated that the combination of HT and anti-HER2 agents can overcome this resistance, at least in part [42, 43]. Vascular endothelial growth factor (VEGF) has also been linked to HT resistance in retrospective studies, although this observation was not validated in prospective studies conducted with bevacizumab, which produced controversial results and failed to prevent the emergence of resistance $[44,45]$. Other markers, such as Ki-67, p53, BCL-2, PI3K, CCDN1, p16, or multigene platforms, have not been useful in therapeutic decision-making [19, 46, 47]. For this reason, these markers must only be considered in the context of clinical trials $[19,46,47]$. Other markers of resistance are estrogen receptor ESR1 gene mutations, which are present in $30 \%$ of metastases in patients who have received HT, but normally absent in the primary tumor [48]. Although these mutations can plausibly be identified, their ability to predict a good response to HT must be validated in prospective studies [48].

Two different scenarios must be considered when establishing the possible definition of primary or secondary hormone resistance. One would be time-dependent, defining relapse after adjuvant treatment, and the other would consider time to progression during the treatment of metastatic disease. If relapse occurs within 2 years after beginning adjuvant HT, or during the first 6 months of first-line HT, experts consider that resistance or insensitivity to HT is primary or intrinsic. In turn, when the diagnosis of relapse occurs more than 2 years after starting adjuvant HT, but within 1 year of completing adjuvant therapy, or if progression occurs later than 6 months after starting HT for metastatic disease, experts consider that resistance is acquired or secondary [19]. Regardless of the time periods, if relapse occurs during adjuvant HT, the disease is resistant to that specific hormonal strategy [49]. The same occurs if metastatic cancer progresses within a period of less than 1 month after discontinuation of such treatment [19, 38, 39, 50]. Table 3 shows some of the definitions used in clinical practice guidelines.

\section{Is there evidence for suggesting that a combination of several hormonal drugs can reverse hormone resistance and increase effectiveness compared to single-agent hormone therapy?}

Two phase III clinical trials exploring this issue in postmenopausal women in first-line treatment for MBC, using a combination of anastrozole and fulvestrant, produced diverging results [1 positive: SWOG 0226 [51] (HR (hazard ratio): $0.81 ; 95 \%$ confidence interval: $0.65-1.00)$, and 1 negative:

Table 3 Main definitions of primary and secondary hormone resistance

\begin{tabular}{|c|c|c|c|}
\hline Reference & Primary hormone resistance & Secondary hormone resistance & $\begin{array}{l}\text { Level of } \\
\text { evidence }\end{array}$ \\
\hline European Consensus guidelines [34] & $\begin{array}{l}\text { Relapse occurred during the first } 2 \text { years of } \\
\text { adjuvant HT, or } \\
\text { Progressive disease in the first } 6 \text { months of HT } \\
\text { in MBC }\end{array}$ & $\begin{array}{l}\text { Relapse occurred after the first } 2 \text { years of } \\
\text { adjuvant HT or in the first year after comple- } \\
\text { tion of adjuvant HT } \\
\text { Progressive disease occurring after the first } \\
6 \text { months of HT in MBC }\end{array}$ & 5 \\
\hline GINECO study [57] & $\begin{array}{l}\text { Relapse during adjuvant HT or in the first } \\
6 \text { months after completion of adjuvant HT } \\
\text { Progressive disease in the first } 6 \text { months of HT } \\
\text { in MBC }\end{array}$ & $\begin{array}{l}\text { Relapse occurring later than } 6 \text { months after } \\
\text { completion of adjuvant HT, or } \\
\text { Progression after } 6 \text { months of starting HT in } \\
\text { MBC }\end{array}$ & 2 \\
\hline Review articles: $[102,103]$ & $\begin{array}{l}\text { Progressive disease without initial response to } \\
\text { treatment }\end{array}$ & $\begin{array}{l}\text { Progressive disease after initial response to } \\
\text { treatment }\end{array}$ & 5 \\
\hline
\end{tabular}


FACT [52] (HR: 1.0; 95\% CI: 0.76-1.32)], although when a subgroup analysis of the SWOG cohort was conducted, there was a significant benefit in OS in patients who had never received adjuvant HT (HR: 0.74; 95\% CI: 0.56-0.98) [51]. The combined meta-analysis of both studies found a marginal but non-significant benefit in PFS (HR: 0.88; 95\% CI: 0.72-1.09) and OS (HR: 0.88; 95\% CI: 0.72-1.08) [53].

Another study in postmenopausal women who had progressed with a non-steroidal aromatase inhibitor (NSAI) did not find any kind of advantage with the combination of anastrozole and fulvestrant in comparison with single-agent fulvestrant or exemestane [54]. In premenopausal women, the combination of ovarian suppression with tamoxifen in first line was superior to ovarian suppression in terms of OS (HR: 0.78; 95\% CI: 0.63-0.96) and PFS (HR: 0.70; 95\% CI: $0.58-0.85)$ [55].

The international guidelines of the European School of Oncology-European Society of Medical Oncology (ESO-ESMO) and ASCO recommend the use of sequential single-agent HT in postmenopausal patients $[19,34]$ and only recommend the combination of anastrozole and fulvestrant in patients who have not received any adjuvant treatment [19]. In the case of premenopausal patients, a combination of ovarian suppression with tamoxifen is recommended in first line, and in subsequent lines, ovarian suppression should be maintained, and patients should be treated in the same way as postmenopausal women [19, 34].

\section{Is there evidence for suggesting that HT combined with chemotherapy can reverse hormone resistance and increase effectiveness compared to single-agent hormone therapy?}

The analysis of some studies suggest that the sequential use of each type of treatment is equivalent to their combination, and data in the adjuvant setting even suggest that combined use may be less effective than sequential use [56]. However, the luminal subtype has not been specifically investigated in any recent study. Therefore, international clinical guidelines do not recommend the combination of HT with chemotherapy $[19,34]$.

\section{Is there evidence for supporting the use of $\mathrm{HT}$ combined with targeted therapies instead of single-agent hormone therapy to reverse hormone resistance and increase effectiveness in HR-positive, HER2-negative MBC?}

One of the possible mechanisms of resistance to HT is activation of the cellular pathways that might interfere with inhibition of the hormone-dependent pathway. One of these pathways is PI3K. Several studies have been published on the mTOR inhibitors, including everolimus and tamoxifen [time to progression (TTP) HR: 0.54; 95\% CI: 0.36-0.81]
[57] and everolimus and exemestane (OS: HR: 0.89; 95\% CI: 0.73-1.10) [58]. As such, everolimus has been approved for use in combination with exemestane after failure of an NSAI, as reflected in international clinical guidelines [19, 34]. Tensirolimus in combination with fulvestrant (PFS: HR: 0.61; 95\% CI: 0.40-0.92) [59] showed a significant increase in PFS. A phase III study evaluated the effect of a combination of tensirolimus and letrozole in first-line therapy, and did not find a benefit in PFS for the combination (HR: 0.90; 95\% CI: 0.76-1.07) [60]. The data on PI3K inhibitors are still very preliminary. The SOLAR-1 study has shown an increase in PFS in second-line treatment in patients with tumors with a PI3K mutation (HR: 0.65 ; 95\% CI: $0.50-0.85$ ) [61].

Two studies in first line with bevacizumab in combination with letrozole produced diverging results, one being negative for PFS (HR: 0.83; 95\% CI: 0.65-1.06) [45] and the other positive (HR: 0.75; 95\% CI: 0.59-0.96) [44]. For this reason, its use has not been recommended in clinical guidelines [62].

The use of anti-EGFR inhibitors (HER1), such as gefitinib, or anti-HER1/2, such as lapatinib, in patients with HRpositive, HER2-negative MBC has not proved effective and is not recommended [63-65].

Three cyclin-D-dependent kinase (CDK)4/6 inhibitors, ribociclib, abemaciclib, and palbociclib, have been studied. In the case of palbociclib, data from two studies (a randomized phase II study [66] and a phase III study [67] in which palbociclib was combined with letrozole in first-line therapy in postmenopausal women) have been published. Both studies showed an increase in PFS with HT alone. There are also data on second-line treatment in combination with fulvestrant, which show an increase in PFS compared to HT alone in both postmenopausal and premenopausal women, associated in the latter with ovarian suppression with luteinizing hormone-releasing hormone (LHRH) analogues (HR: 0.49; 95\% CI: 0.32-0.75) and HR: 0.50; 95\% CI: 0.33-0.76], respectively) $[38,68]$. In the case of ribociclib, data have been published on a phase III study in first line in postmenopausal women, in which it was combined with letrozole, showing an increase in PFS compared to HT alone (HR: 0.56; 95\% CI: 0.43-0.72) [69]. In the case of abemaciclib, data have been published from two studies: a phase III study, in which abemaciclib was combined with an NSAI, anastrozole, or letrozole, in first line [70] and another phase III study in which it was combined with fulvestrant in second line [71]; in both cases an increase in PFS was found compared with HT alone (HR: 0.54; 95\% CI: 0.41-0.72 and HR: 0.55; 95\% CI: 0.45-0.68), respectively). Data have also been presented from a phase II study of abemaciclib monotherapy in patients polytreated with HT and chemotherapy, showing a response rate of up to $17 \%$ [72].

Table 4 shows the recommendations of the expert group with regard to hormone resistance and hormone sensitivity. 
Table 4 Recommendations and conclusions on the definition of hormone sensitivity-hormone resistance in metastatic luminal disease

\begin{tabular}{|c|c|c|}
\hline & LA $(\%)$ & $\mathrm{LE} / \mathrm{RD}$ \\
\hline $\begin{array}{l}\text { Negativization }(<1 \%) \text { of hormone receptors in metastatic cells should be considered as hormone resistance, so ER, PR and } \\
\text { HER2 of a new metastasis should be determined whenever possible before making therapeutic decisions (expert opinion) }\end{array}$ & 95 & 5 \\
\hline $\begin{array}{l}\text { A high level of hormone receptors makes hormone sensitivity more likely. However, there is no accurate cutoff point or score } \\
\text { that indicates hormone resistance, so any tumor with ER } \geq 1 \% \text { can theoretically be hormone sensitive (expert opinion) }\end{array}$ & 93 & 5 \\
\hline $\begin{array}{l}\text { The only unequivocal criterion of hormone resistance is progression during a hormonal intervention. Progressive disease } \\
\text { during the first } 6 \text { months of HT for MB or during the first } 2 \text { years of (neo-)adjuvant HT is evidence of resistance to hormone } \\
\text { therapy, so the line of treatment must be changed }[19,50]\end{array}$ & 97 & 2 \\
\hline $\begin{array}{l}\text { Intracellular signaling markers and ER mutations (ESR1) should not be taken into account when deciding to use HT outside } \\
\text { the setting of a clinical trial }[19,37]\end{array}$ & 93 & 2/B \\
\hline $\begin{array}{l}\text { In the context of disease relapse after adjuvant treatment, progression occurring during the first } 2 \text { years of adjuvant treatment } \\
\text { can be considered as primary or refractory hormone resistance [34] }\end{array}$ & 97 & 5 \\
\hline In the context of MBC, progression in the first 6 months of HT can be considered primary hormone resistance [34] & 97 & 5 \\
\hline $\begin{array}{l}\text { Insufficient evidence was found to answer this question. However, in the context of relapse during or after adjuvant treatment, } \\
\text { relapse occurring later than } 2 \text { years after starting treatment and within } 1 \text { year after completion could be considered second- } \\
\text { ary hormone resistance [34] }\end{array}$ & 95 & 5 \\
\hline $\begin{array}{l}\text { In the context of metastatic disease, progressive disease after an initial benefit with HT within the first } 6 \text { months of treatment } \\
\text { is considered secondary hormone resistance [34] }\end{array}$ & 92 & 5 \\
\hline $\begin{array}{l}\text { In postmenopausal women, there is insufficient evidence to recommend the combination of two hormone agents simultane- } \\
\text { ously. Thus, HT in sequential monotherapy is recommended }[19,34]\end{array}$ & 97 & $1 / \mathrm{A}$ \\
\hline $\begin{array}{l}\text { In the case of premenopausal women, a combination of ovarian suppression with tamoxifen or AI in first line is recommended } \\
{[19,34]}\end{array}$ & 95 & $1 / \mathrm{B}$ \\
\hline $\begin{array}{l}\text { In premenopausal women, ovarian suppression should be maintained and sequential HT should be added as in postmenopau- } \\
\text { sal women in second line and in subsequent lines }[19,34]\end{array}$ & 93 & $3 / \mathrm{C}$ \\
\hline $\begin{array}{l}\text { In patients with HR-positive, HER2-negative advanced breast cancer, the use of a combination of TH and chemotherapy is } \\
\text { recommended. Sequential administration is recommended, with HT being the preferred option in first line and in succes- } \\
\text { sive lines until the emergence of resistance. The use of chemotherapy as a first option is preferable in a critical situation of } \\
\text { visceral disease requiring a quick response }[19,34,56]\end{array}$ & 99 & $2 / \mathrm{C}$ \\
\hline $\begin{array}{l}\text { In postmenopausal patients, cyclin-dependent kinase inhibitors ribociclib and palbociclib in combination with an NSAI are } \\
\text { recommended as a treatment option in first-line HT. Palbociclib is also recommended in second line in combination with } \\
\text { fulvestrant after failure on first-line therapy (palbociclib is also indicated in premenopausal* patients in combination with an } \\
\text { NSAI or fulvestrant with an LHRH analog) }[38,66-69,74]\end{array}$ & 97 & $1 / \mathrm{A}$ \\
\hline $\begin{array}{l}\text { In postmenopausal patients, the combination of exemestane with everolimus is recommended in the absence of symptomatic } \\
\text { visceral disease after failure of an NSAI. The use of mTOR inhibitors is not recommended in patients who have not previ- } \\
\text { ously received an NSAI or in cases of MBC de novo or those who have relapsed after more than } 1 \text { year after the end of } \\
\text { adjuvant treatment }[19,34]\end{array}$ & 97 & 2/B \\
\hline The use of antiangiogenic drugs in combination with HT is not recommended $[19,34]$ & 89 & $2 / \mathrm{B}$ \\
\hline The use of HER1/2 inhibitors in combination with HT in HR-positive, HER2-negative MBC is not recommended [63-65] & 95 & $2 / \mathrm{B}$ \\
\hline
\end{tabular}

$E R$ estrogen receptor, ESR1 estrogen receptor 1, HER2 human epidermal growth factor receptor 2, $H T$ Hormone therapy, $L A$ level of agreement, $L E$ level of evidence, $M B C$ metastatic breast cancer, $m T O R$ mammalian target of rapamycin, NSAI non-steroidal aromatase inhibitors, $P R$ progesterone receptor, $R D$ recommendation degree according to Oxford

*Currently, ribociclib and abemaciclib are also indicated in premenopausal patients. Palbociclib is the only cyclin-dependent kinase inhibitor mentioned because ribociclib and abemaciclib had not still the indication in this subgroup of patients when the external validation using a tworound Delphi technique was done

\section{Therapeutic decision-making}

\section{Can the menopausal status influence the selection of first-line treatment? Should ovarian function be suppressed in first-line treatment?}

The selection of the optimal HT in patients with HR-positive, HER2-negative MBC should be guided by menopausal status, previously administered HT, and the patient's comorbidities $[19,73]$. Very few clinical trials have included premenopausal women in their designs, especially in firstline strategies [74]. The choice of treatment in first line depends on the adjuvant treatment, which may be chemical or surgical castration [19]. Studies comparing the effectiveness of tamoxifen and oophorectomy in this type of patients found no significant differences for the various clinical parameters under study $[75,76]$. LHRH analogs with or without tamoxifen had similar results to oophorectomy [77]. The combination of LHRH analogs and tamoxifen 
was superior to tamoxifen in terms of response rate, TTP, and OS [78].

\section{What are the criteria for tumor "aggressiveness" in luminal MBC that would indicate the need for chemotherapy?}

Several studies have demonstrated similar rates of disease control and OS (HR: 0.94; 95\% CI: 0.79-1.12) between HT and chemotherapy [79]. Although chemotherapy can achieve a greater number of responses, the toxicity profile favors HT. In addition, the presence of visceral disease (non-lifethreatening) has not been shown to reduce the benefit of HT. Numerous reviews highlight HT as the treatment of choice in first line and in subsequent lines of treatment in HR-positive, HER2-negative MBC, reserving chemotherapy for cases with imminent failure of a vital organ [56, 80], symptomatic visceral disease, and/or rapid growth [56, $80,81]$, or HT resistance, including previous combinations of HT and targeted therapies, such as mTOR inhibitors or cyclin-dependent kinase inhibitors, the aim of which is to delay or reverse the development of this endocrine resistance $[81,82]$. These results have prompted clinical practice guidelines such as ASCO to consider chemotherapy as an appropriate initial treatment in patients with imminent lifethreatening disease, in whom the time to response can be critical. It may also be considered as a first option in patients with low HR levels in whom HT may be less effective [19]. The ESO-ESMO clinical guidelines for MBC also assert the recommendation to reserve chemotherapy for cases with rapidly progressive disease or confirmed endocrine resistance. In other situations, HT is still the first option, even in the presence of visceral disease [34]. The National Breast and Ovarian Cancer Center (NBOCC) guidelines also recommend using chemotherapy only in cases of rapidly progressing visceral disease [83]. The Canadian guidelines offer alternatives in postmenopausal women with HR-positive, HER2-negative MBC who relapse or progress after treatment with an NSAI, proposing other hormone treatments or a combination of everolimus and exemestane in patients with endocrine resistance and slow progression. Chemotherapy

Table 5 Recommendations on therapeutic decision-making

\begin{tabular}{|c|c|c|}
\hline & LA (\%) & LE/RD \\
\hline $\begin{array}{l}\text { Menopausal status should not be taken into account when deciding whether to use chemotherapy or HT in patients with ER- } \\
\text { positive, HER2-negative MBC [79] }\end{array}$ & 89 & $5 / \mathrm{D}$ \\
\hline $\begin{array}{l}\text { Menopausal status should be taken into account when selecting HT in patients with ER-positive, HER2-negative disease [19, } \\
\text { 73] }\end{array}$ & 90 & $5 / \mathrm{D}$ \\
\hline $\begin{array}{l}\text { In premenopausal patients with ER-positive } \mathrm{MBC} \text {, ovarian ablation in combination with another HT should be recommended. } \\
\text { In patients who have never received HT or who relapse more than } 12 \text { months after completing adjuvant HT, combined ovar- } \\
\text { ian ablation or suppression should be recommended }[75,76]\end{array}$ & 96 & $2 / \mathrm{B}$ \\
\hline $\begin{array}{l}\text { In premenopausal patients with ER-positive MBC who have never received HT or who relapse after } 12 \text { months since complet- } \\
\text { ing adjuvant } \mathrm{HT} \text {, ovarian suppression or ablation should be recommended in combination with tamoxifen or AI } \pm \text { cyclin } \\
\text { inhibitors as first-line treatment, provided that there is no visceral crisis [55] }\end{array}$ & 97 & $1 / \mathrm{A}$ \\
\hline $\begin{array}{l}\text { In premenopausal patients with ER-positive MBC who relapse during adjuvant HT or in the } 12 \text { months after completion of } \\
\text { adjuvant HT, ovarian ablation could be combined with an AI or fulvestrant, as in postmenopausal patients, although the } \\
\text { evidence is still inadequate [78] }\end{array}$ & 93 & $3 / \mathrm{C}$ \\
\hline $\begin{array}{l}\text { Suggested criteria for tumor "aggressiveness" in luminal MBC that would indicate the need for treatment with chemotherapy } \\
\text { are as follows: } \\
\text { Rapidly progressing or very symptomatic disease } \\
\text { Disease compromising a vital organ or imminent risk to life } \\
\text { Disease with demonstrated endocrine resistance, even after previous treatment with targeted therapies (mTOR or cyclin } \\
\text { inhibitors, for example) casting doubt on the possible response to HT (expert opinion) }\end{array}$ & 99 & $5 / \mathrm{D}$ \\
\hline $\begin{array}{l}\text { Serum markers may not be used as the sole criterion for defining progression (resistance) or for starting, stopping or changing } \\
\text { HT. However, progressive and sustained elevation (two determinations more than } 1 \text { month apart) of CA } 15.3 \text { and/or CEA } \\
\text { could be useful in unmeasurable disease to raise suspicion of progression (resistance) and to request imaging tests to confirm } \\
\text { progression (evaluation of PET/CT) (expert opinion) }\end{array}$ & 97 & $5 / \mathrm{D}$ \\
\hline $\begin{array}{l}\text { In the event of a sustained elevation of serum marker CA15.3 and/or CEA during HT, imaging studies should be requested to } \\
\text { document any progression/hormone resistance. At this stage, PET/CT is more sensitive than conventional methods, espe- } \\
\text { cially in the evaluation of pathological axillary, supraclavicular, internal mammary chain, and mediastinal lymphadenopa- } \\
\text { thies }[56,85]\end{array}$ & 90 & $3 / \mathrm{C}$ \\
\hline $\begin{array}{l}\text { CTC and circulating c-erbB-2 extracellular domain should not be used as the sole criterion to start, stop or change HT [19, 34, } \\
37,88]\end{array}$ & 9 & $2 / \mathrm{C}$ \\
\hline
\end{tabular}

$A I$ aromatase inhibitor, $C T C$ circulating tumor cell, $E R$ estrogen receptor, $H E R 2$ human epidermal growth factor receptor 2 , $H T$ hormone therapy, $L E$ level of evidence, $L A$ level of agreement, $M B C$ metastatic breast cancer, $m T O R$ mammalian target of rapamycin, $P E T$ positron emission tomography, $R D$ recommendation degree according to Oxford 
is limited to patients with resistance to HT and symptomatic visceral disease [78]. The Spanish Society of Medical Oncology (SEOM) guidelines for MBC published in 2018 specify that chemotherapy should be standard treatment in patients who are refractory to HT [84].

\section{Are serum biomarkers useful?}

A series of serum biomarkers has emerged in recent years, including CA15.3, CEA, CA 27.29, circulating tumor cells (CTC), and circulating erbB-2 extracellular domain that could help determine resistance to hormonal interventions. Some prospective studies have shown that the combination of several of these serum markers, such as CEA and CA 15.3 [85, 86], or CTC and CA 27.29 [87], is more sensitive than using them singly in the diagnosis of metastatic relapse. However, randomized phase III studies have not shown any survival benefit from the serial determination of serum markers [88], nor is there any evidence that initiating or changing treatment on the basis of serum markers or CTC confers an improvement in health status, survival, or quality of life [19, 34, 37, 88]. Three expert consensus articles also agree that no well-designed studies are available to evaluate the clinical utility of the markers $[19,34,37]$. Nevertheless, this is the only method for monitoring unevaluable metastatic disease [19, 34, 37, 85, 86].

Table 5 shows the recommendations of the expert group with regard to therapeutic decision-making.

\section{Discussion}

Consensus documents prepared by independent committees are a valuable tool for decision-making in areas in which evidence is limited or could not be combined to establish clinical strategies or improve efficiency in the delivery of health services [9]. The preparation of this consensus document has been sponsored by the GEICAM Breast Cancer Research Group, and is the product of the dedicated involvement of the members of the GEICAM Luminal Disease Working Group. This consensus was developed following a robust, recognized, and rigorous methodology, but a number of limitations inherent to documents of this type must be taken into account. In the first place, the review of the literature, while systematic, was not exhaustive, and only the most current publications were included. Furthermore, after the initial literature review, the development of recommendations and consensus took longer than expected, which is why, after they were completed, we had to perform an additional search to update specific themes to take into account recent advances in the treatment of luminal MBC. The following is a summary of the main results of this additional review.
With respect to the combination of everolimus with HT, results have been published showing that the combination of everolimus with fulvestrant in second-line therapy increases PFS from 5.1 to 10.3 months (HR: 0.61 ; 95\% CI: 0.40-0.92) [89], results that are in line with data from the phase III study of everolimus plus exemestane [90]. With regard to PI3K inhibitors (selective or pan-PI3K inhibitors), the results of phase III trials of buparlisib [91, 92] and taselisib [93], both in combination with fulvestrant, have recently been published. Toward the end of 2018, data were presented on alpelisib (a selective inhibitor of the PI3K alpha subunit) in combination with fulvestrant showing increased PFS in patients with PIK3CA mutations [61]. While the first two showed positive but clinically non-significant results, the selective inhibitor alpelisib did yield data on statistically significant efficacy and clinically manageable safety in the second-line treatment of patients with ER+/HER2-/PI3CAmutated breast cancer. With regard to CDK4/6 inhibitors, the results of phase III studies of ribociclib combined with tamoxifen and LHRH analogs in first line in premenopausal patients [94] and with fulvestrant in first and second line in postmenopausal patients [95] have been published, showing the same benefit in PFS. These results give greater coherence to the use of CDK4/6 inhibitors in combination with HT in the first- or second-line treatment of luminal MBC. Finally, data were presented at ASCO 2019 on the impact on OS of ribociclib combined with HT in premenopausal patients who, for the first time, showed an increase in OS with the combination of HT and CDK4/6 inhibitors [96], and later in ESMO 2019 the benefit in OS has been presented in other two trials, one for the combination of ribociclib with fulvestrant in first and second line in postmenopausal women (MONALEESA3) [97] and the other for abemaciclib in combination with fulvestrant in second line [98].

The classification of luminal subtypes A and B is based on gene expression and their correlation with immunohistochemistry is not complete. There is no evidence to suggest that the subclassification of luminal type A or B using immunohistochemical techniques, in the absence of other factors, should influence therapeutic decision-making. A meta-analysis which included the analysis of 39 studies found that the conversion rates of receptors in metastasis of advanced breast cancer patients are high. It is recommended that biopsies are performed to confirm the status of these receptors in metastasis, although more prospective studies would need to be conducted to determine whether this conversion has some type of impact on the effectiveness of treatment in terms of survival [99].

Medical oncology is a field in which new data are constantly emerging. These updates oblige us to respond to questions that arise from the new evidence, including, for example, the diagnostic role of new technologies, such as genomic platforms and liquid biopsy. Other areas of 
therapeutic interest might be determining suitable patient profiles for biologics and combination therapies (HT with biologics), as well as their sequence. Other issues might address those profiles in which chemotherapy will be more effective or the duration of administration of antiresorptive therapies. With regard to follow-up, questions are being raised on the aggressiveness of tumors that have developed resistance to cyclin-dependent kinase inhibitors, the role of fulvestrant in first line to avoid the appearance of ESR1 mutations, and quality of life issues. Other questions to be resolved surround the primary objectives of clinical trials and the role of combined therapies in advanced luminal cancer. Answers to these and other questions should become available from future studies to be able to continue offering improvements in the treatment of patients with advanced luminal breast cancer.

Acknowledgements The authors would like to thank the support received by Novartis Farmacéutica S.A. for the realization of this project, as well as the technical assistance provided by Susana Bezares and Marta del Campo of GEICAM. They also want to thank the methodological editorial assistance of Verónica Albert, Aina Batlle and Antoni Torres of GOC Networking throughout the project. The authors extend their gratitude to all the members of the panel of experts who participated in the Delphi validation round (in alphabetical order): José Enrique Alés Martínez, Hospital Nuestra Señora de Sonsoles (Ávila); Iñaki Álvarez Busto, Hospital Universitario Miguel Servet (Zaragoza); Silvia Antolín Novoa, Complejo Hospitalario Universitario de A Coruña (La Coruña); Àngels Arcusa Lanza, Consorci Sanitari de Terrassa (Barcelona); Anabel Ballesteros García, Hospital Universitario de la Princesa (Madrid); Juan Antonio Barrera Ramírez, Hospital Marina Baixa Villajoyosa / San Joan Alacant (Alicante); Begoña Bermejo de las Heras, Hospital Clínico Universitario (Valencia); Coralia Bueno Muiño, Hospital Infanta Cristina (Madrid); Isabel Calvo Plaza, MD Anderson Cancer Center (Madrid); Lourdes Calvo Martínez, Complejo Hospitalario Universitario A Coruña (La Coruña); Blanca Cantos Sánchez de Ibargüen, Hospital Universitario Puerta de Hierro Majadahonda (Madrid); Isaac Ceballos Lenza, Hospital Universitario de Canarias (Sta. Cruz de Tenerife); Verónica Conde Herrero, Hospital Universitario Virgen de las Nieves (Granada); Josefina Cruz Jurado, Hospital Universitario de Canarias (Sta. Cruz de Tenerife); Susana de la Cruz Sánchez, Complejo Hospitalario de Navarra (Navarra); Nieves Díaz Fernández, Hospital Universitario San Juan de Alicante (Alicante); Joan Dorca Ribugent, Institut Català d'Oncologia Girona (Gerona); Antonio Fernández Aramburo, Complejo Hospitalario Universitario de Albacete (Albacete); Concha Fernández-Chacón de Lucas, Hospital La Zarzuela (Madrid); Luis Antonio FernándezMorales, Hospital Universitario Parc Taulí Sabadell (Barcelona); Jesús Florián Gericó, Hospital de Barbastro (Huesca); Elena Galve Calvo, Hospital de Basurto (Vizcaya); Paula García Teijido, Hospital San Agustín de Avilés (Asturias); César Gómez Raposo, Hospital Universitario Infanta Sofía (Madrid); Encarna González Flores, Hospital Universitario Virgen de las Nieves (Granada); Sonia González Jiménez, Hospital Universitari Mútua Terrassa (Barcelona); Begoña Graña Suárez, Complejo Hospitalario Universitario A Coruña (La Coruña); Juan Antonio Guerra Martínez, Hospital Universitario de Fuenlabrada (Madrid); Vega Iranzo González-Cruz, Consorcio Hospital General Universitario Valencia (Valencia); Yann Izarzugaza Perón, Fundación Jiménez Díaz (Madrid); Yolanda Jerez Gilarranz, Hospital General Universitario Gregorio Marañón (Madrid); Montse Llobera Serentill, Hospital de Tortosa Verge de la Cinta (Tarragona); Gemma Llort Pursals, Hospital Universitari Parc Taulí Sabadell (Barcelona);
María Lomas Garrido, Hospital Médico Quirúrgico de Jaén (Jaén); Sara López-Tarruella Cobo, Hospital General Universitario Gregorio Marañón (Madrid); Isabel Lorenzo Lorenzo, Complejo Hospitalario Universitario de Vigo (Pontevedra); Mireia Margelí Vila, Institut Català d’Oncologia Badalona (Barcelona); Antonia Martínez Guisado, Hospital Universitario Torrecárdenas (Almería); María José Martínez-Ortiz, Hospital Universitario Santa Lucía (Murcia); Fernando Moreno Antón, Hospital Clínico San Carlos (Madrid); Alberto Luis Moreno Vega, Hospital Reina Sofía (Córdoba); María del Mar Muñoz Sánchez, Hospital General Virgen de la Luz (Cuenca); Berta Obispo Portero, Hospital Universitario Infanta Leonor (Madrid); Belén Ojeda González, Hospital Delfos (Barcelona); Amparo Oltra Ferrando, Hospital Virgen de los Lirios (Alicante); Ignacio Peláez Fernández, Hospital Universitario de Cabueñes (Asturias); Quionia Pérez Arnillas, Hospital Clínico Universitario de Valladolid (Valladolid); Cristina Pérez Segura, Hospital Sant Pau i Santa Tecla (Tarragona); Sonia Pernàs Simon, Institut Català d’Oncologia (Barcelona); María Teresa Quintanar Verdúguez, Hospital General Universitario de Elche (Alicante); César Augusto Rodríguez Sánchez, Hospital Universitario de Salamanca (Salamanca); Álvaro Rodríguez Lescure, Hospital General Universitario de Elche (Alicante); Manuel Ruíz Borrego, Hospital Virgen del Rocío (Sevilla); Isabel Ruiz Cabrero, Hospital de Sant Pau i Santa Tecla (Tarragona); Alfonso Sánchez Muñoz, Hospitales Universitarios Regional y Virgen de la Victoria (Málaga); Marta Santisteban Eslava, Clínica Universidad de Navarra (Navarra); Miguel Ángel Seguí Palmer, Hospital Universitari Parc Taulí Sabadell (Barcelona); Sonia Servitja Tormo, Hospital del Mar (Barcelona); Agostina Stradella, Institut Català d'Oncologia (Barcelona); Ander Urruticoechea Ribate, Fundación Onkologikoa (Guipúzcoa); Silvia Varela Ferreiro, Hospital Universitario Lucus Augusti (Lugo); María Vidal Losada, Hospital Clínic (Barcelona); Rafael Villanueva Vázquez, Institut Català d’Oncologia (Barcelona).

Funding The development of this work has been possible thanks to the financial support of Novartis Oncology.

\section{Compliance with ethical standards}

Conflict of interest IMAL declares consultancy/speaker fees from Novartis, Pfizer, Palex and Roche, institution research funding from Astra Zeneca, Roche, Novartis and Pfizer and travel support from Roche, Pfizer and Eisai. JAGS declares consultancy/speaker fees from Novartis, Celgene, Eli Lilly, EISAI and Roche, institution research funding from Astra Zeneca and travel support from Novartis, Roche and Pfizer. MGG declares personal fees from Novartis, Pfizer, Genomic Health Roche, Daiichi-Sankyo and Eisai. NRE declares consultancy/speaker fees from Novartis, Roche and Pfizer and travel support from Novartis, Roche and Pfizer. SBM declares grants from Novartis to GEICAM SPANISH BREAST CANCER GROUP, during the conduct of the study. ED declares personal fees from Roche, Pfizer, Novartis, Eisai, and Lilly. EM declares consultancy/speaker fees from Novartis, EISAI, Roche and Pfizer, institution research funding from Astra Zeneca and travel support from Roche. ASB declares consultancy/speaker fees from Roche, Novartis, Astra-Zeneca, Tesaro, Clovis, Amgen, MSD and Pfizer. She also declares registration and attending scientific meetings at Pfizer, Roche, Pharmamar and MSD.

Ethical approval The study has been performed in accordance with the ethical standards of the Declaration of Helsinki and its later amendments. This article does not contain any data derived from studies with human participants or animals performed by any of the authors.

Informed consent None. 
Open Access This article is licensed under a Creative Commons Attribution 4.0 International License, which permits use, sharing, adaptation, distribution and reproduction in any medium or format, as long as you give appropriate credit to the original author(s) and the source, provide a link to the Creative Commons licence, and indicate if changes were made. The images or other third party material in this article are included in the article's Creative Commons licence, unless indicated otherwise in a credit line to the material. If material is not included in the article's Creative Commons licence and your intended use is not permitted by statutory regulation or exceeds the permitted use, you will need to obtain permission directly from the copyright holder. To view a copy of this licence, visit http://creativecommons.org/licenses/by/4.0/.

\section{References}

1. European Cancer Information System. 2019. https://ecis.jrc. ec.europa.eu/explorer.php?\$0-0\$1-All\$2-All\$4-1,2\$3-29\$60,14\$5-2008,2008\$7-7\$CEstByCountry\$X0_8-3\$X0_19-AE28E \$X0_20-No\$CEstRelative\$X1_8-3\$X1_9-AE28\$X1_19-AE28E \$CEstByCountryTable\$X2_19-AE28E. Accessed April 2019.

2. El cáncer de mama en España-Geicam-Investigación en Cáncer de Mama. 2019. https://www.geicam.org/sala-de-prensa/el-cance r-de-mama-en-espana. Accessed April 2019.

3. Las cifras de cáncer en España 2019. Sociedad Española de Oncología Médica (SEOM). 2019. https://seom.org/dmcancer/ wp-content/uploads/2019/Informe-SEOM-cifras-cancer-2019. pdf. Accessed April 2019.

4. GEICAM (Grupo Español de Investigación en Cáncer de Mama). Guía Resumida para el Diagnóstico y Tratamiento del Cáncer de Mama Metastásico. Guía GEICAM de Práctica Clínica. 2015.

5. Cheng YC, Ueno NT. Improvement of survival and prospect of cure in patients with metastatic breast cancer. Breast Cancer. 2012;19:191-9.

6. Gavila J, Lopez-Tarruella S, Saura C, Munoz M, Oliveira M, De la Cruz-Merino L, et al. SEOM clinical guidelines in metastatic breast cancer 2015. Clin Transl Oncol. 2015;17:946-55.

7. OncoGuía de mama. Guías de práctica clínica en cáncer de Catalunya. 2003. Actualización 2008.

8. Cardoso F, Costa A, Senkus E, Aapro M, Andre F, Barrios CH, et al. 3rd ESO-ESMO international consensus guidelines for advanced breast cancer (ABC 3). Ann Oncol. 2017;28:16-33.

9. Oishi SM, Morton SC, Moore AA, Beck JC, Hays RD, Spritzer $\mathrm{KL}$, et al. Using data to enhance the expert panel process. Rating indications of alcohol-related problems in older adults. Int J Technol Assess Health Care. 2001;17:125-36.

10. Brook R. The RAND/UCLA appropriateness method. Methodology perspectives. MD: AHCPR Pub; 1994.

11. Elkins MY. Using PICO and the brief report to answer clinical questions. Nursing. 2010;40:59-60.

12. Oxford Centre for Evidence-Based Medicine. Levels of Evidence Document. 2011. https://www.cebm.net/wp-content/uploa ds/2014/06/CEBM-Levels-of-Evidence-2.1.pdf. Accessed Jan 2017.

13. Hammond ME, Hayes DF, Dowsett M, Allred DC, Hagerty KL, Badve S, et al. American Society of Clinical Oncology/College of American Pathologists guideline recommendations for immunohistochemical testing of estrogen and progesterone receptors in breast cancer (unabridged version). Arch Pathol Lab Med. 2010;134:e48-72.

14. Allred DC, Carlson RW, Berry DA, Burstein HJ, Edge SB, Goldstein LJ, et al. NCCN task force report: estrogen receptor and progesterone receptor testing in breast cancer by immunohistochemistry. J Natl Compr Canc Netw. 2009;7(Suppl 6):S1-S21 quiz S2-S3.

15. Prat A, Perou CM. Deconstructing the molecular portraits of breast cancer. Mol Oncol. 2011;5:5-23.

16. Falato C, Tobin NP, Lorent J, Lindstrom LS, Bergh J, Foukakis T. Intrinsic subtypes and genomic signatures of primary breast cancer and prognosis after systemic relapse. Mol Oncol. 2016;10:517-25.

17. Prat A, Cheang MC, Galvan P, Nuciforo P, Pare L, Adamo B, et al. Prognostic value of intrinsic subtypes in hormone receptorpositive metastatic breast cancer treated with letrozole with or without lapatinib. JAMA Oncol. 2016;2:1287-94.

18. King TA, Lyman JP, Gonen M, Voci A, De Brot M, Boafo $\mathrm{C}$, et al. Prognostic impact of 21-gene recurrence score in patients with stage IV breast cancer: TBCRC 013. J Clin Oncol. 2016;34:2359-65.

19. Rugo HS, Rumble RB, Macrae E, Barton DL, Connolly HK, Dickler MN, et al. Endocrine therapy for hormone receptorpositive metastatic breast cancer: American Society of Clinical Oncology Guideline. J Clin Oncol. 2016;34:3069-103.

20. Cheang MC, Chia SK, Voduc D, Gao D, Leung S, Snider J, et al. Ki67 index, HER2 status, and prognosis of patients with luminal B breast cancer. J Natl Cancer Inst. 2009;101:736-50.

21. Prat A, Cheang MC, Martin M, Parker JS, Carrasco E, Caballero $\mathrm{R}$, et al. Prognostic significance of progesterone receptor-positive tumor cells within immunohistochemically defined luminal A breast cancer. J Clin Oncol. 2013;31:203-9.

22. Goldhirsch A, Wood WC, Coates AS, Gelber RD, Thurlimann B, Senn HJ, et al. Strategies for subtypes-dealing with the diversity of breast cancer: highlights of the St. Gallen International Expert Consensus on the Primary Therapy of Early Breast Cancer 2011. Ann Oncol. 2011;22:1736-47.

23. Goldhirsch A, Winer EP, Coates AS, Gelber RD, Piccart-Gebhart $\mathrm{M}$, Thurlimann B, et al. Personalizing the treatment of women with early breast cancer: highlights of the St Gallen International Expert Consensus on the Primary Therapy of Early Breast Cancer 2013. Ann Oncol. 2013;24:2206-23.

24. Falato C, Lorent J, Tani E, Karlsson E, Wright PK, Bergh J, et al. Ki67 measured in metastatic tissue and prognosis in patients with advanced breast cancer. Breast Cancer Res Treat. 2014;147:407-14.

25. Rocca A, Farolfi A, Maltoni R, Carretta E, Melegari E, Ferrario $\mathrm{C}$, et al. Efficacy of endocrine therapy in relation to progesterone receptor and Ki67 expression in advanced breast cancer. Breast Cancer Res Treat. 2015;152:57-655.

26. Delpech Y, Wu Y, Hess KR, Hsu L, Ayers M, Natowicz R, et al. Ki67 expression in the primary tumor predicts for clinical benefit and time to progression on first-line endocrine therapy in estrogen receptor-positive metastatic breast cancer. Breast Cancer Res Treat. 2012;135:619-27.

27. Nelli F, Natoli G, Moscetti L, Massari A, D’Auria G, Fabbri MA, et al. Epirubicin and docetaxel as first-line treatment for hormonal receptor positive metastatic breast cancer: the predictive value of luminal subtype: a retrospective cohort analysis. J Chemother. 2013;25:112-8.

28. Smith IE, Dowsett M. Aromatase inhibitors in breast cancer. N Engl J Med. 2003;348:2431-42.

29. Clemons M, Simmons C. Identifying menopause in breast cancer patients: considerations and implications. Breast Cancer Res Treat. 2007;104:115-20.

30. Aksoy S, Dizdar O, Altundag K. Definition of postmenopausal status, age of the breast cancer patients and the outcome of aromatase inhibitors treatment. Breast. 2008;5:433-5.

31. Cejalvo JM, Martinez de Duenas E, Galvan P, Garcia-Recio S, Burgues Gasion O, Pare L, et al. Intrinsic subtypes and gene 
expression profiles in primary and metastatic breast cancer. Cancer Res. 2017;77:2213-21.

32. de Duenas EM, Hernandez AL, Zotano AG, Carrion RM, Lopez-Muniz JI, Novoa SA, et al. Prospective evaluation of the conversion rate in the receptor status between primary breast cancer and metastasis: results from the GEICAM 2009-03 ConvertHER study. Breast Cancer Res Treat. 2014;143:507-15.

33. Amir E, Clemons M, Purdie CA, Miller N, Quinlan P, Geddie W, et al. Tissue confirmation of disease recurrence in breast cancer patients: pooled analysis of multi-centre, multi-disciplinary prospective studies. Cancer Treat Rev. 2012;38:708-14.

34. Cardoso F, Costa A, Norton L, Senkus E, Aapro M, Andre F, et al. ESO-ESMO 2nd international consensus guidelines for advanced breast cancer (ABC2). Breast. 2014;23:489-502 .

35. Untch M, Augustin D, Ettl J, Haidinger R, Harbeck N, Luck $\mathrm{HJ}$, et al. $\mathrm{ABC} 3$ consensus commented from the perspective of the German guidelines: Third International Consensus Conference for Advanced Breast Cancer (ABC3), Lisbon, 07.11.2015. Geburtshilfe Frauenheilkd. 2016;76:156-63.

36. Gradishar WJ, Anderson BO, Balassanian R, Blair SL, Burstein $\mathrm{HJ}$, Cyr A, et al. NCCN guidelines insights breast cancer, version 1.2016. J Natl Compr Canc Netw. 2015;13:1475-85.

37. Van Poznak C, Somerfield MR, Bast RC, Cristofanilli M, Goetz MP, Gonzalez-Angulo AM, et al. Use of biomarkers to guide decisions on systemic therapy for women with metastatic breast cancer: American Society of Clinical Oncology Clinical Practice Guideline. J Clin Oncol. 2015;33:2695-704.

38. Turner NC, Ro J, Andre F, Loi S, Verma S, Iwata H, et al. Palbociclib in hormone-receptor-positive advanced breast cancer. $\mathrm{N}$ Engl J Med. 2015;373:209-19.

39. Baselga J, Campone M, Piccart M, Burris HA 3rd, Rugo HS, Sahmoud T, et al. Everolimus in postmenopausal hormonereceptor-positive advanced breast cancer. N Engl J Med. 2012;366:520-9.

40. Gonzalez-Angulo AM, Morales-Vasquez F, Hortobagyi GN. Overview of resistance to systemic therapy in patients with breast cancer. Adv Exp Med Biol. 2007;608:1-22.

41. Amir E, Miller N, Geddie W, Freedman O, Kassam F, Simmons $\mathrm{C}$, et al. Prospective study evaluating the impact of tissue confirmation of metastatic disease in patients with breast cancer. $\mathrm{J}$ Clin Oncol. 2012;30:587-92.

42. von Minckwitz G, du Bois A, Schmidt M, Maass N, Cufer T, de Jongh FE, et al. Trastuzumab beyond progression in human epidermal growth factor receptor 2-positive advanced breast cancer: a german breast group 26/breast international group 03-05 study. J Clin Oncol. 2009;27:1999-2006.

43. Huober J, Fasching PA, Barsoum M, Petruzelka L, Wallwiener D, Thomssen C, et al. Higher efficacy of letrozole in combination with trastuzumab compared to letrozole monotherapy as firstline treatment in patients with HER2-positive, hormone-receptorpositive metastatic breast cancer-results of the eLEcTRA trial. Breast. 2012;21:27-33.

44. Dickler MN, Barry WT, Cirrincione CT, Ellis MJ, Moynahan $\mathrm{ME}$, Innocenti F, et al. Phase III trial evaluating letrozole as firstline endocrine therapy with or without bevacizumab for the treatment of postmenopausal women with hormone receptor-positive advanced-stage breast cancer: CALGB 40503 (alliance). J Clin Oncol. 2016;34:2602-9.

45. Martin M, Loibl S, von Minckwitz G, Morales S, Martinez N, Guerrero A, et al. Phase III trial evaluating the addition of bevacizumab to endocrine therapy as first-line treatment for advanced breast cancer: the letrozole/fulvestrant and avastin (LEA) study. J Clin Oncol. 2015;33:1045-52.

46. DeMichele A, Clark AS, Tan KS, Heitjan DF, Gramlich K, Gallagher M, et al. CDK 4/6 inhibitor palbociclib (PD0332991) in
$\mathrm{Rb}+$ advanced breast cancer: phase II activity, safety, and predictive biomarker assessment. Clin Cancer Res. 2015;21:995-1001.

47. Kroger N, Milde-Langosch K, Riethdorf S, Schmoor C, Schumacher M, Zander AR, et al. Prognostic and predictive effects of immunohistochemical factors in high-risk primary breast cancer patients. Clin Cancer Res. 2006;12:159-68.

48. Angus L, Beije N, Jager A, Martens JW, Sleijfer S. ESR1 mutations: moving towards guiding treatment decision-making in metastatic breast cancer patients. Cancer Treat Rev. 2017;52:33-40.

49. Gligorov J, Lotz JP. Optimal treatment strategies in postmenopausal women with hormone-receptor-positive and HER2negative metastatic breast cancer. Breast Cancer Res Treat. 2008;112(Suppl 1):53-66.

50. Cardoso F, Costa A, Senkus E, Aapro M, Andre F, Barrios CH, et al. 3rd ESO-ESMO International Consensus Guidelines for Advanced Breast Cancer (ABC 3). Ann Oncol. 2017;28:3111.

51. Mehta RS, Barlow WE, Albain KS, Vandenberg TA, Dakhil SR, Tirumali NR, et al. Combination anastrozole and fulvestrant in metastatic breast cancer. N Engl J Med. 2012;367:435-44.

52. Bergh J, Jonsson PE, Lidbrink EK, Trudeau M, Eiermann W, Brattstrom D, et al. FACT: an open-label randomized phase III study of fulvestrant and anastrozole in combination compared with anastrozole alone as first-line therapy for patients with receptor-positive postmenopausal breast cancer. J Clin Oncol. 2012;30:1919-25.

53. Tan PS, Haaland B, Montero AJ, Lopes G. A meta-analysis of anastrozole in combination with fulvestrant in the first line treatment of hormone receptor positive advanced breast cancer. Breast Cancer Res Treat. 2013;138:961-5.

54. Johnston SR, Kilburn LS, Ellis P, Dodwell D, Cameron D, Hayward L, et al. Fulvestrant plus anastrozole or placebo versus exemestane alone after progression on non-steroidal aromatase inhibitors in postmenopausal patients with hormone-receptorpositive locally advanced or metastatic breast cancer (SoFEA): a composite, multicentre, phase 3 randomised trial. Lancet Oncol. 2013;14:989-98.

55. Klijn JG, Blamey RW, Boccardo F, Tominaga T, Duchateau L, Sylvester R, et al. Combined tamoxifen and luteinizing hormonereleasing hormone (LHRH) agonist versus LHRH agonist alone in premenopausal advanced breast cancer: a meta-analysis of four randomized trials. J Clin Oncol. 2001;19:343-53.

56. Higgins MJ, Wolff AC. Therapeutic options in the management of metastatic breast cancer. Oncology. 2008;22:614-23 discussion 23, 27-29.

57. Bachelot T, Bourgier C, Cropet C, Ray-Coquard I, Ferrero JM, Freyer G, et al. Randomized phase II trial of everolimus in combination with tamoxifen in patients with hormone receptor-positive, human epidermal growth factor receptor 2-negative metastatic breast cancer with prior exposure to aromatase inhibitors: a GINECO study. J Clin Oncol. 2012;30:2718-24.

58. Piccart M, Hortobagyi GN, Campone M, Pritchard KI, Lebrun F, Ito $\mathrm{Y}$, et al. Everolimus plus exemestane for hormone-receptorpositive, human epidermal growth factor receptor-2-negative advanced breast cancer: overall survival results from BOLERO2dagger. Ann Oncol. 2014;25:2357-62.

59. Kornblum N, Manola J, Klein P, Ramaswamy B, Brufsky A, Stella P et al. PrECOG 0102: a randomized, double-blind, phase II trial of fulvestrant plus everolimus or placebo in post-menopausal women with HR-positive, HER2-negative MBC resistant to AI therapy. In: 39th San Antonio Breast Cancer Symposium (SABCS), San Antonio; 2017.

60. Wolff AC, Lazar AA, Bondarenko I, Garin AM, Brincat S, Chow L, et al. Randomized phase III placebo-controlled trial of letrozole plus oral temsirolimus as first-line endocrine therapy in postmenopausal women with locally advanced or metastatic breast cancer. J Clin Oncol. 2013;31:195-202. 
61. Andre F, Ciruelos E, Rubovszky G, Campone M, Loibl S, Rugo HS, et al. Alpelisib for PIK3CA-mutated, hormone receptor-positive advanced breast cancer. N Engl J Med. 2019;380:1929-40.

62. Martin M, Loibl S, Hyslop T, De la Haba-Rodriguez J, Aktas B, Cirrincione CT, et al. Evaluating the addition of bevacizumab to endocrine therapy as first-line treatment for hormone receptorpositive metastatic breast cancer: a pooled analysis from the LEA (GEICAM/2006-11_GBG51) and CALGB 40503 (alliance) trials. Eur J Cancer. 2019;117:91-8.

63. Carlson RW, O'Neill A, Vidaurre T, Gomez HL, Badve SS, Sledge GW. A randomized trial of combination anastrozole plus gefitinib and of combination fulvestrant plus gefitinib in the treatment of postmenopausal women with hormone receptor positive metastatic breast cancer. Breast Cancer Res Treat. 2012;133:1049-56.

64. Johnston S, Pippen J Jr, Pivot X, Lichinitser M, Sadeghi S, Dieras V, et al. Lapatinib combined with letrozole versus letrozole and placebo as first-line therapy for postmenopausal hormone receptor-positive metastatic breast cancer. J Clin Oncol. 2009;27:5538-46.

65. Guerra YC, Chan A, Finkelstein DM, Chan VF, Harvey VJ, Lee $\mathrm{KS}$, et al. Lack of efficacy of adjuvant lapatinib in HER2-negative breast cancer (HER2-ve BC): analysis of patients in the TEACH trial. J Clin Oncol. 2013;31:628.

66. Finn RS, Crown JP, Lang I, Boer K, Bondarenko IM, Kulyk $\mathrm{SO}$, et al. The cyclin-dependent kinase 4/6 inhibitor palbociclib in combination with letrozole versus letrozole alone as firstline treatment of oestrogen receptor-positive, HER2-negative, advanced breast cancer (PALOMA-1/TRIO-18): a randomised phase 2 study. Lancet Oncol. 2015;16:25-35.

67. Finn RS, Martin M, Rugo HS, Jones S, Im SA, Gelmon K, et al. Palbociclib and letrozole in advanced breast cancer. N Engl J Med. 2016;375:1925-36.

68. Cristofanilli M, Turner NC, Bondarenko I, Ro J, Im SA, Masuda $\mathrm{N}$, et al. Fulvestrant plus palbociclib versus fulvestrant plus placebo for treatment of hormone-receptor-positive, HER2-negative metastatic breast cancer that progressed on previous endocrine therapy (PALOMA-3): final analysis of the multicentre, double-blind, phase 3 randomised controlled trial. Lancet Oncol. 2016;17:425-39.

69. Hortobagyi GN, Stemmer SM, Burris HA, Yap YS, Sonke GS, Paluch-Shimon S, et al. Ribociclib as first-line therapy for hr-positive, advanced breast cancer. N Engl J Med. 2016;375:1738-48.

70. Goetz MP, Toi M, Campone M, Sohn J, Paluch-Shimon S, Huober J, et al. MONARCH 3: abemaciclib as initial therapy for advanced breast cancer. J Clin Oncol. 2017;35:3638-46.

71. Sledge GW Jr, Toi M, Neven P, Sohn J, Inoue K, Pivot X, et al. MONARCH 2: abemaciclib in combination with fulvestrant in women with HR+/HER2- advanced breast cancer who had progressed while receiving endocrine therapy. J Clin Oncol. 2017;35:2875-84.

72. Dickler MN, Tolaney SM, Rugo HS, Cortes J, Dieras V, Patt D, et al. MONARCH 1, a phase II study of abemaciclib, a CDK4 and CDK6 inhibitor, as a single agent, in patients with refractory HR(+)/HER2(-) metastatic breast cancer. Clin Cancer Res. 2017;23:5218-24.

73. Ganz PA. Breast cancer, menopause, and long-term survivorship: critical issues for the 21st century. Am J Med. 2005;118(Suppl 12B): $136-41$.

74. Tripathy D, Sohn J, Im S-A, et al. First-line ribociclib vs placebo with goserelin and tamoxifen or a non-steroidal aromatase inhibitor in premenopausal women with hormone receptor-positive, HER2-negative advanced breast cancer: results from the randomized phase III MONALEESA-7 trial. In: GS2-05 SA, editor. 2017.
75. Ingle JN, Krook JE, Green SJ, Kubista TP, Everson LK, Ahmann DL, et al. Randomized trial of bilateral oophorectomy versus tamoxifen in premenopausal women with metastatic breast cancer. J Clin Oncol. 1986;4:178-85.

76. Crump M, Sawka CA, DeBoer G, Buchanan RB, Ingle JN, Forbes J, et al. An individual patient-based meta-analysis of tamoxifen versus ovarian ablation as first line endocrine therapy for premenopausal women with metastatic breast cancer. Breast Cancer Res Treat. 1997;44:201-10.

77. Boccardo F, Rubagotti A, Perrotta A, Amoroso D, Balestrero M, De Matteis A, et al. Ovarian ablation versus goserelin with or without tamoxifen in pre-perimenopausal patients with advanced breast cancer: results of a multicentric Italian study. Ann Oncol. 1994;5:337-42.

78. Klijn JG, Beex LV, Mauriac L, van Zijl JA, Veyret C, Wildiers $\mathrm{J}$, et al. Combined treatment with buserelin and tamoxifen in premenopausal metastatic breast cancer: a randomized study. J Natl Cancer Inst. 2000;92:903-11.

79. Wilcken N, Hornbuckle J, Ghersi D. Chemotherapy alone versus endocrine therapy alone for metastatic breast cancer. The Cochrane database of systematic reviews. 2003;CD002747.

80. Gogineni K, DeMichele A. Current approaches to the management of Her2-negative metastatic breast cancer. Breast Cancer Res. 2012;14:205.

81. Telli ML, Carlson RW. First-line chemotherapy for metastatic breast cancer. Clin Breast Cancer. 2009;9(Suppl 2):S66-72.

82. Brufsky AM. Delaying chemotherapy in the treatment of hormone receptor-positive, human epidermal growth factor receptor 2-negative advanced breast cancer. Clin Med Insights Oncol. 2015;9:137-47.

83. National Breast and Ovarian Cancer Centre. Recommendations for use of endocrine therapy for the treatment of hormone receptor-positive advanced breast cancer. NSW: National Breast and Ovarian Cancer Centre; 2010.

84. Chacon Lopez-Muniz JI, de la Cruz ML, Gavila Gregori J, Martinez Duenas E, Oliveira M, Segui Palmer MA, et al. SEOM clinical guidelines in advanced and recurrent breast cancer (2018). Clin Transl Oncol. 2019;21:31-45.

85. Seregni E, Coli A, Mazzucca N, Italian Group Ria-Irma Test IAoNM. Circulating tumour markers in breast cancer. Eur J Nucl Med Mol Imaging. 2004;31(Suppl 1):S15-S22.

86. Cheung KL, Robertson FR. Objective measurement of remission and progression in metastatic breast cancer by the use of serum tumour markers. Minerva Chir. 2003;58:297-303.

87. Hepp P, Andergassen U, Jager B, Trapp E, Alunni-Fabbroni M, Friedl TW, et al. Association of CA27.29 and circulating tumor cells before and at different times after adjuvant chemotherapy in patients with early-stage breast cancer-the SUCCESS trial. Anticancer Res. 2016;36:4771-6.

88. Lumachi F, Basso SM. Serum tumor markers in patients with breast cancer. Expert Rev Anticancer Ther. 2004;4:921-31.

89. Kornblum N, Zhao F, Manola J, Klein P, Ramaswamy B, Brufsky A, et al. Randomized phase II trial of fulvestrant plus everolimus or placebo in postmenopausal women with hormone receptorpositive, human epidermal growth factor receptor 2-negative metastatic breast cancer resistant to aromatase inhibitor therapy: results of PrE0102. J Clin Oncol. 2018;36:1556-633.

90. Yardley DA, Noguchi S, Pritchard KI, Burris HA 3rd, Baselga J, Gnant M, et al. Everolimus plus exemestane in postmenopausal patients with $\mathrm{HR}(+)$ breast cancer: BOLERO-2 final progressionfree survival analysis. Adv Ther. 2013;30:870-84.

91. Di Leo A, Johnston S, Lee KS, Ciruelos E, Lonning PE, Janni W, et al. Buparlisib plus fulvestrant in postmenopausal women with hormone-receptor-positive, HER2-negative, advanced breast cancer progressing on or after mTOR inhibition (BELLE-3): 
a randomised, double-blind, placebo-controlled, phase 3 trial. Lancet Oncol. 2018;19:87-100.

92. Campone M, Im SA, Iwata H, Clemons M, Ito Y, Awada A, et al. Buparlisib plus fulvestrant versus placebo plus fulvestrant for postmenopausal, hormone receptor-positive, human epidermal growth factor receptor 2-negative, advanced breast cancer: overall survival results from BELLE-2. Eur J Cancer. 2018;103:147-54.

93. Baselga J, Dent SF, Cortés J, Im Y-H, Diéras V, Harbeck N, et al. Phase III study of taselisib (GDC-0032) + fulvestrant (FULV) $\mathrm{v}$ FULV in patients (pts) with estrogen receptor (ER)-positive, PIK3CA-mutant (MUT), locally advanced or metastatic breast cancer (MBC): primary analysis from SANDPIPER. J Clin Oncol. 2018;36:LBA1006.

94. Tripathy D, Im SA, Colleoni M, Franke F, Bardia A, Harbeck $\mathrm{N}$, et al. Ribociclib plus endocrine therapy for premenopausal women with hormone-receptor-positive, advanced breast cancer (MONALEESA-7): a randomised phase 3 trial. Lancet Oncol. 2018;19:904-15.

95. Slamon DJ, Neven P, Chia S, Fasching PA, De Laurentiis M, Im $\mathrm{SA}$, et al. Phase III randomized study of ribociclib and fulvestrant in hormone receptor-positive, human epidermal growth factor receptor 2-negative advanced breast cancer: MONALEESA-3. J Clin Oncol. 2018;36:2465-72.

96. Im SA, Lu YS, Bardia A, Harbeck N, Colleoni M, Franke F, et al. Overall survival with ribociclib plus endocrine therapy in breast cancer. N Engl J Med. 2019;381:307-16.

97. Slamon DJ, Neven P, Chia S, Fasching PA, De Laurentiis M, Im SA et al. LBA7_PR: Overall survival (OS) results of the phase III MONALEESA-3 trial of postmenopausal patients (pts) with hormone receptor-positive (HR+), human epidermal growth factor 2-negative (HER2-) advanced breast cancer (ABC) treated with fulvestrant $(\mathrm{FUL}) \pm$ ribociclib (RIB). Ann Oncol 2019;30:v851-934.

98. Sledge GW Jr, Toi M, Neven P, Sohn J, Inoue K, Pivot X, et al. The effect of abemaciclib plus fulvestrant on overall survival in hormone receptor-positive, ERBB2-negative breast cancer that progressed on endocrine therapy-MONARCH 2: a randomized clinical trial. JAMA Oncol.2020;6:116-124.

99. Schrijver W, Suijkerbuijk KPM, van Gils CH, van der Wall E, Moelans CB, van Diest PJ. Receptor conversion in distant breast cancer metastases: a systematic review and meta-analysis. J Natl Cancer Inst. 2018;110:568-80.

100. Gradishar WJ, Anderson BO, Balassanian R, Blair SL, Burstein HJ, Cyr A, et al. Breast cancer, version 2. 2015. J Natl Compr Canc Netw. 2015;13:448-75.

101. Sarri G, Davies M, Lumsden MA, Guideline DG. Diagnosis and management of menopause: summary of NICE guidance. BMJ. 2015;351:h5746.

102. Martin LA, Andre F, Campone M, Bachelot T, Jerusalem G. mTOR inhibitors in advanced breast cancer: ready for prime time? Cancer Treat Rev. 2013;39:742-52.

103. Gluck S. Extending the clinical benefit of endocrine therapy for women with hormone receptor-positive metastatic breast cancer: differentiating mechanisms of action. Clin Breast Cancer. $2014 ; 14: 75-84$.

Publisher's Note Springer Nature remains neutral with regard to jurisdictional claims in published maps and institutional affiliations. 